\title{
Sediminibacterium salmoneum gen. nov., sp. nov., a member of the phylum Bacteroidetes isolated from sediment of a eutrophic reservoir
}

\author{
Jian-Hang Qu and Hong-Li Yuan
}

Correspondence

Hong-Li Yuan

hlyuan@cau.edu.cn

\author{
College of Biological Sciences, Key Laboratory of Agro-Microbial Resource and Application, \\ Ministry of Agriculture, China Agricultural University, Beijing 100094, PR China
}

During the study of the bacterial community in the sediment of a eutrophic reservoir, a novel salmon-pinkpigmented bacterium, designated $\mathrm{NJ}-44^{\mathrm{T}}$, was isolated. A polyphasic study suggested that strain $\mathrm{NJ}-44^{\mathrm{T}}$ was most closely related to members of the genera Terrimonas, Niabella and Niastella of the phylum Bacteroidetes. Xie \& Yokota (2006) described the genus Terrimonas to group the novel species Terrimonas lutea and Flavobacterium ferrugineum, a Gram-negative, aerobic, non-motile, soil organism. The genus Terrimonas has recently been included in the family Crenotrichaceae along with its close relative Chitinophaga (Garrity et al., 2007). The other two recently described genera, Niabella and Niastella, were proposed by Kim et al. (2007) and Weon et al. (2006), respectively, for several soil isolates. They include Niabella aurantiaca, Niastella yeongjuensis and Niastella koreensis. In this study, polyphasic results showed that strain $\mathrm{NJ}-44^{\mathrm{T}}$ represents a novel genus and species in the phylum Bacteroidetes related to, but distinct from, members of the genera Terrimonas, Niabella and Niastella.

Strain NJ-44 ${ }^{\mathrm{T}}$ was isolated from sediment of the seriously eutrophic Guanting Reservoir in Beijing (China). Characteristics of the sampled sediment were $\mathrm{pH} 7.7$,

The GenBank/EMBL/DDBJ accession number for the $16 \mathrm{~S}$ rRNA gene sequence of strain $\mathrm{NJ}-44^{\top}$ is EF407879.

Maximum-parsimony and minimum-evolution phylogenetic trees based on 16S rRNA gene sequences are available as supplementary material with the online version of this paper.
$276.54 \mathrm{mg}$ microbial biomass carbon $\mathrm{kg}^{-1}, 3.92 \%$ organic carbon, $0.48 \%$ total nitrogen, $0.04 \%$ available $\mathrm{K}$ and $8.2 \mathrm{mg}$ available $\mathrm{P} \mathrm{kg}^{-1}$.

For isolation, serially diluted sediment samples were spread onto plates of sediment steep medium prepared as follows: $400 \mathrm{~g}$ sediment was boiled in $1 \mathrm{l}$ distilled water for $10 \mathrm{~min}$ and $0.5 \mathrm{~g}$ peptone, $0.5 \mathrm{~g}$ yeast extract and $15 \mathrm{~g}$ agar were then added to 11 supernatant; the $\mathrm{pH}$ was not adjusted. Plates were incubated at $28{ }^{\circ} \mathrm{C}$ for 10 days. A single colony of strain $\mathrm{NJ}-44^{\mathrm{T}}$ was picked and subcultured on modified R2A medium (yeast extract, $0.5 \mathrm{~g}$; polypeptone, $0.5 \mathrm{~g}$; Casamino acids, $0.5 \mathrm{~g}$; glucose, $0.5 \mathrm{~g}$; soluble starch, $0.5 \mathrm{~g}$; $\mathrm{K}_{2} \mathrm{HPO}_{4}, 0.3 \mathrm{~g} ; \mathrm{MgSO}_{4} .7 \mathrm{H}_{2} \mathrm{O}, 0.05 \mathrm{~g}$; distilled water $1 \mathrm{l}$; $\mathrm{pH}$ 7.2).

Cell morphology was observed under an Olympus light microscope at $\times 1000$ with cells grown on R2A agar for 2 days at $28{ }^{\circ} \mathrm{C}$. Growth at $4,18,22,28,37$ and $50{ }^{\circ} \mathrm{C}$ and $\mathrm{pH} 5,5.5,6.0,6.5,7.0,7.5,8.0$ and 8.5 was assessed after 10 days of incubation. The $\mathrm{pH}$ of R2A broth was adjusted by adding $1 \mathrm{M} \mathrm{NaOH}$ or $1 \mathrm{M} \mathrm{HCl}$. Tolerance to salinity was tested in R2A broth supplemented with $0-5.0 \% \mathrm{NaCl}$ $(\mathrm{w} / \mathrm{v})$ at $1 \%$ intervals after 10 days of incubation. Growth on nutrient agar (NA), trypticase soy agar (TSA), marine agar 2216 (MA) and PYG agar was also evaluated at $28^{\circ} \mathrm{C}$ for 10 days. All media were prepared in the laboratory following the composition of Difco media (NA, TSA and MA) or according to Zhu et al. (2003) (PYG). Flexirubintype pigments were sought by flooding a small mass of bacterial cells with $20 \% \mathrm{KOH}$ according to Bernardet et al. 
(2002). Motility was investigated using the hanging drop technique with fresh cells in $\mathrm{R} 2 \mathrm{~A}$ broth. Utilization of carbon and energy sources was investigated in a basal medium containing $\left(1^{-1}\right) 1 \mathrm{~g}\left(\mathrm{NH}_{4}\right)_{2} \mathrm{HPO}_{4}, 0.1 \mathrm{~g}$ yeast extract, $0.3 \mathrm{~g} \mathrm{~K}_{2} \mathrm{HPO}_{4}$ and $0.05 \mathrm{~g} \mathrm{MgSO}_{4} .7 \mathrm{H}_{2} \mathrm{O}, \mathrm{pH}$ 7.2. Carbon substrates were added at a concentration of $0.5 \%$ $(\mathrm{w} / \mathrm{v})$. All other biochemical tests were carried out according to Dong \& Cai (2001). Cells grown in R2A broth for 3 days at $28{ }^{\circ} \mathrm{C}$ were used for cellular fatty acid analysis. Fatty acid methyl esters were prepared and identified using the Sherlock Microbial Identification System (MIDI) according to the manufacturer's instructions. Genomic DNA was extracted according to Marmur (1961) and Johnson (1985a, b) from cells cultured for 2 days in R2A broth. The $\mathrm{G}+\mathrm{C}$ content of the DNA was determined by thermal denaturation (De Ley, 1970) using DNA from Escherichia coli $\mathrm{K}-12$ as a control. The phenotypic characteristics of strain $\mathrm{NJ}-44^{\mathrm{T}}$ are given in the species description and in Table 1.

The 16S rRNA gene of strain NJ-44 ${ }^{\mathrm{T}}$ was amplified by PCR using the bacterial universal primers 27F and 1495R (Ying et al., 2007) and a 1458 bp sequence was obtained with an ABI 3730 XL 96-capillary sequencer (Applied Biosystems).
The identification of phylogenetic neighbours and calculation of pairwise $16 \mathrm{~S}$ rRNA gene sequence similarity were achieved using the EzTaxon server (http://www.eztaxon. org/; Chun et al., 2007). Further analysis performed using MEGA version 3.1 (Kumar et al., 2004) showed that strain $\mathrm{NJ}-44^{\mathrm{T}}$ was related to Terrimonas ferruginea, Terrimonas lutea, Niabella aurantiaca, Niastella yeongjuensis and Niastella koreensis, with 88.9-90.8\% 16S rRNA gene sequence similarity to the type strains. Phylogenetic trees were constructed with MEGA version 3.1 after multiple alignment of data by CLUSTAL W (Thompson et al., 1994). With three different algorithms (neighbour-joining, minimum-evolution and maximum-parsimony), strain NJ-44 ${ }^{\mathrm{T}}$ clustered with members of the genera Niabella and Terrimonas. The neighbour-joining tree is shown in Fig. 1. The topology of the tree was evaluated by using Kimura's two-parameter calculation model (Kumar et al., 2004) based on 1000 replicates. As shown in Fig. 1, strain NJ-44 ${ }^{\mathrm{T}}$, Niabella aurantiaca R2A15-11 ${ }^{\mathrm{T}}$, T. ferruginea ATCC $13524^{\mathrm{T}}$ and T. lutea $\mathrm{DY}^{\mathrm{T}}$ formed a branch that shared less than $90 \%$ sequence similarity with members of the genera Niastella and Chitinophaga, though similarity between the latter was also about $90 \%$. The minimum-evolution and

Table 1. Differential characteristics of strain $\mathrm{NJ}-44^{\top}$ and type strains of related species

Strains: 1, Sediminibacterium salmoneum gen. nov., sp. nov. NJ-44 ${ }^{\mathrm{T}} ; 2$, Terrimonas ferruginea $\mathrm{IAM} 15098^{\mathrm{T}} ; 3$, Terrimonas lutea IAM $15284^{\mathrm{T}}$; 4 , Niabella aurantiaca R2A15-11 $1^{\mathrm{T}} ; 5$, Niastella yeongjuensis DSM $17621^{\mathrm{T}} ; 6$, Niastella koreensis DSM $17620^{\mathrm{T}} ; 7$, Chitinophaga pinensis ACM $2034^{\mathrm{T}}$. Data for reference strains were taken from Xie \& Yokota (2006), Kim et al. (2007), Weon et al. (2006) and Kämpfer et al. (2006). +, Positive; -, negative; w, weakly positive; ND, no data available.

\begin{tabular}{|c|c|c|c|c|c|c|c|}
\hline Characteristic & 1 & 2 & 3 & 4 & 5 & 6 & 7 \\
\hline Pigmentation* & SP & SR & $\mathrm{Y}$ & $\mathrm{O}$ & $\mathrm{M}$ & LY & $\mathrm{Y}$ \\
\hline \multicolumn{8}{|l|}{ Production of: } \\
\hline Flexirubin-type pigments & - & ND & ND & + & - & - & $\mathrm{ND}$ \\
\hline $\mathrm{H}_{2} \mathrm{~S}$ & + & - & - & ND & ND & $\mathrm{ND}$ & - \\
\hline Oxidase & + & + & + & - & + & - & + \\
\hline Catalase & + & $\mathrm{W}$ & $\mathrm{w}$ & + & - & - & + \\
\hline$\beta$-Galactosidase & + & + & - & + & + & + & ND \\
\hline Urease & - & - & - & - & - & - & + \\
\hline Gliding motility & + & - & - & - & + & + & + \\
\hline Nitrate reduction & - & + & + & - & - & - & $\mathrm{ND}$ \\
\hline Growth at $37^{\circ} \mathrm{C}$ & + & + & + & ND & - & + & + \\
\hline Highest $\mathrm{NaCl}$ tolerance $(\%)$ & 1.0 & 1.0 & 1.0 & 3.0 & ND & ND & ND \\
\hline \multicolumn{8}{|l|}{ Hydrolysis of: } \\
\hline Chitin & - & - & - & - & + & + & + \\
\hline CM-cellulose & - & ND & ND & - & + & + & ND \\
\hline Casein & - & ND & ND & + & + & + & $\mathrm{ND}$ \\
\hline \multicolumn{8}{|l|}{ Assimilation of: } \\
\hline Arabinose & - & - & + & + & - & - & + \\
\hline Trehalose & + & - & + & ND & $\mathrm{ND}$ & $\mathrm{ND}$ & $\mathrm{ND}$ \\
\hline D-Xylose & - & + & - & ND & ND & ND & ND \\
\hline Melibiose & + & - & + & + & - & - & - \\
\hline Sucrose & + & - & + & + & - & - & + \\
\hline Rhamnose & - & + & - & + & - & - & + \\
\hline DNA G $+\mathrm{C}$ content $(\mathrm{mol} \%)$ & 40.6 & 48.9 & 47.2 & 45.0 & 44.3 & 45.8 & 45.2 \\
\hline
\end{tabular}

${ }^{\star}$ LY, Light yellow; M, milky; O, orange; SP, salmon pink; SR, salmon red; Y, yellow. 


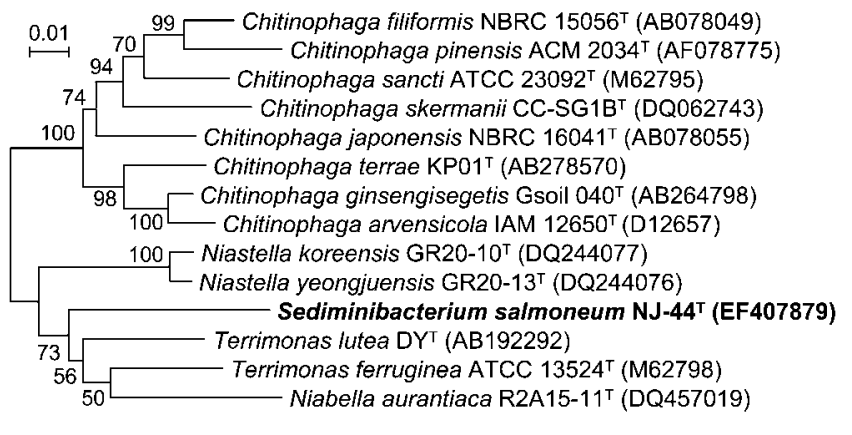

Fig. 1. Neighbour-joining tree based on the 16S rRNA gene sequences of strain $\mathrm{NJ}-44^{\top}$ and members of the genera Terrimonas, Niabella, Niastella and Chitinophaga. Numbers at nodes indicate bootstrap percentages $>50 \%$ from 1000 replicates. Bar, 0.01 substitutions per nucleotide position.

maximum-parsimony trees (available as Supplementary Fig. S1 in IJSEM Online) showed essentially the same topology.
The major cellular fatty acids of strain $\mathrm{NJ}-44^{\mathrm{T}}$ were iso- $\mathrm{C}_{15: 1}$ $\mathrm{G}$, iso- $\mathrm{C}_{15: 0}$, anteiso- $\mathrm{C}_{15: 0}$, iso- $\mathrm{C}_{16: 0} 3-\mathrm{OH}$, iso- $\mathrm{C}_{17: 0} 3-$ $\mathrm{OH}$, anteiso- $\mathrm{C}_{15: 1} \mathrm{~A}$ and iso- $\mathrm{C}_{15: 0} 3-\mathrm{OH}$, clearly distinguishing it from Terrimonas and Niabella species (Table 2).

The DNA G $+\mathrm{C}$ content of strain $\mathrm{NJ}-44^{\mathrm{T}}$ was $40.6 \mathrm{~mol} \%$, well below those of Terrimonas species (47.2-48.9 mol\%; Xie \& Yokota, 2006) and Niabella aurantiaca (45.0 mol\%; Kim et al., 2007).

Data from 16S rRNA gene sequencing studies, cellular fatty acid composition and DNA G $+\mathrm{C}$ content showed that strain NJ-44 ${ }^{\mathrm{T}}$ cannot be assigned to the genera Terrimonas or Niabella, although they represent its closest phylogenetic neighbours. On the basis of phylogenetic and phenotypic data, it is proposed that strain NJ-44 ${ }^{\mathrm{T}}$ represents a new genus and species, for which the name Sediminibacterium salmoneum gen. nov., sp. nov. is proposed.

\section{Description of Sediminibacterium gen. nov.}

Sediminibacterium (Se'di.mi.ni.bac.te' ri.um. L. n. sedimen -inis sediment; L. neut. n. bacterium a rod; N.L. neut. n. Sediminibacterium a rod from sediment).

Table 2. Cellular fatty acid compositions of strain $\mathrm{NJ}-44^{\top}$ and type strains of related species

Strains: 1, Sediminibacterium salmoneum gen. nov., sp. nov. NJ-44 ${ }^{\mathrm{T}} ; 2$, Terrimonas ferruginea IAM $15098^{\mathrm{T}} ; 3$, Terrimonas lutea IAM $15284^{\mathrm{T}} ; 4$, Niabella aurantiaca R2A15-11 ${ }^{\mathrm{T}} ; 5$, Niastella yeongjuensis DSM $17621^{\mathrm{T}} ; 6$, Niastella koreensis DSM $17620^{\mathrm{T}} ; 7$, Chitinophaga pinensis ACM $2034^{\mathrm{T}}$. Data for reference strains were taken from Xie \& Yokota (2006), Kim et al. (2007), Weon et al. (2006) and Kämpfer et al. (2006). Some of the strains listed were grown under different culture conditions. Values are percentages of total fatty acids; fatty acids amounting to less than $1 \%$ of total fatty acids in all strains studied are not listed. tr, Traces $(<1 \%)$.

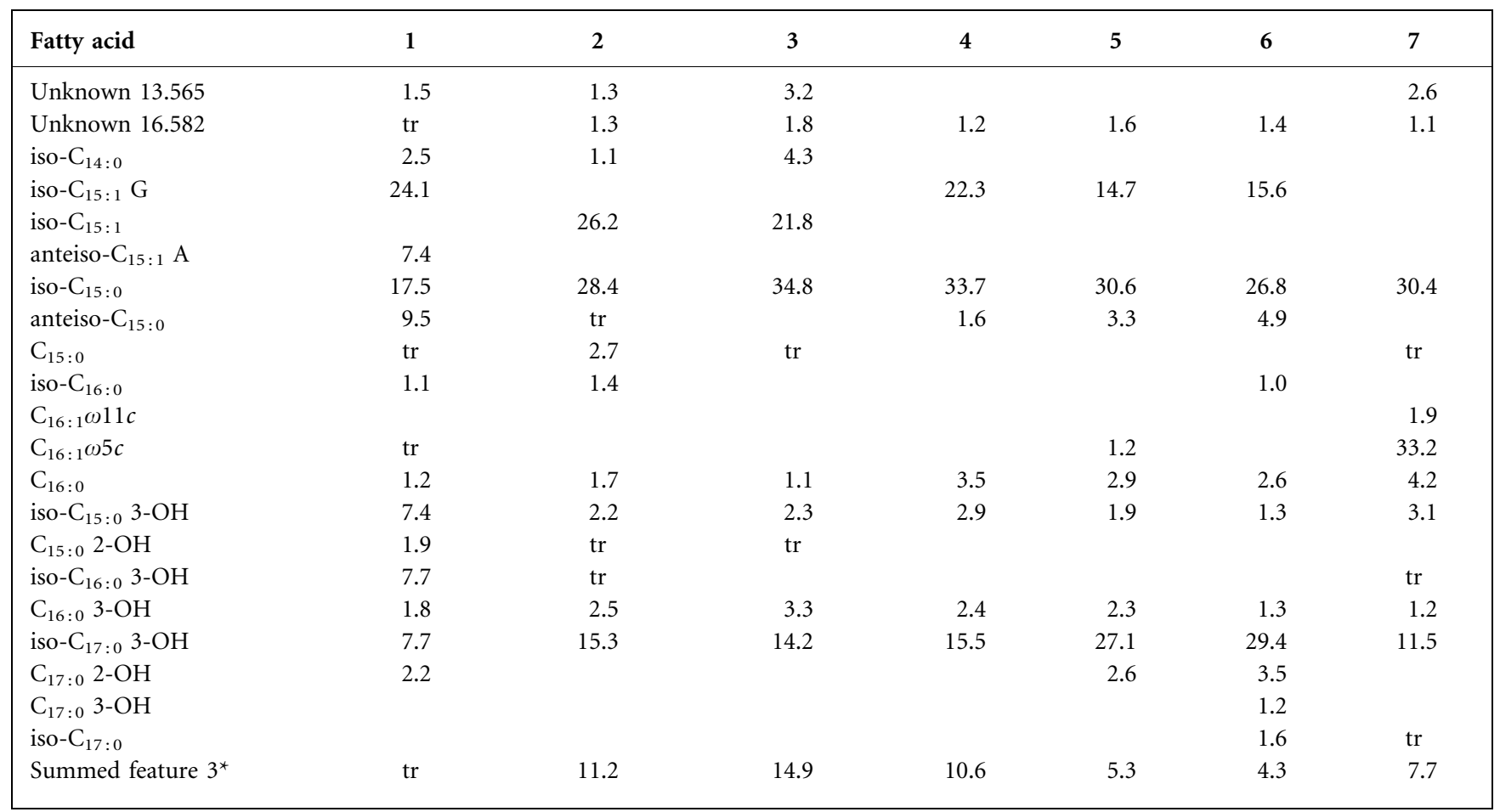

${ }^{*}$ Summed features are combinations of fatty acids that cannot be separated by the MIDI system. Summed feature 3 comprises iso- $\mathrm{C}_{15: 0} 2-\mathrm{OH}$ and/ or $\mathrm{C}_{16: 1} \omega 7 c$. 
Cells are strictly aerobic, Gram-negative rods. Oxidase- and catalase-positive. Flexirubin-type pigments are absent. The major cellular fatty acids are iso- $\mathrm{C}_{15: 1} \mathrm{G}$, iso- $\mathrm{C}_{15: 0}$, anteiso- $\mathrm{C}_{15: 0}$, iso- $\mathrm{C}_{16: 0} 3-\mathrm{OH}$, iso- $\mathrm{C}_{17: 0} 3-\mathrm{OH}$, anteiso$\mathrm{C}_{15: 1} \mathrm{~A}$ and iso- $\mathrm{C}_{15: 0}$ 3-OH. The type species is Sediminibacterium salmoneum. Phylogenetically related to the genera Terrimonas and Niabella in the phylum Bacteroidetes.

\section{Description of Sediminibacterium salmoneum sp. nov.}

Sediminibacterium salmoneum (sal.mo.ne'um. L. n. salmo -onis salmon; L. adj. suff. -eus - $a$-um suffix used with various meanings; N.L. neut. adj. salmoneum salmon-coloured).

The characteristics are the same as those given in the genus description. Cells are single rods, $0.2-0.3 \mu \mathrm{m}$ in diameter and 1.0-1.2 $\mu \mathrm{m}$ long, with gliding motility. Colonies on R2A agar are salmon-pink, circular, about $0.5-1 \mathrm{~mm}$ in diameter and non-spreading after 3 days of incubation at $28{ }^{\circ} \mathrm{C}$. Growth occurs at $18-37{ }^{\circ} \mathrm{C}$ (optimum, $22-28{ }^{\circ} \mathrm{C}$ ), at $\mathrm{pH}$ 6.0-7.5 (optimum, 7.0) and with up to $1 \% \mathrm{NaCl}$ (optimum growth in the absence of $\mathrm{NaCl}$ ). No growth occurs on TSA, NA, MA or PYG agar. $\mathrm{H}_{2} \mathrm{~S}$ is produced. Nitrate is not reduced. $o$-Nitrophenyl $\beta$-D-galactopyranoside (ONPG) is hydrolysed. Gelatin is degraded but pectin, chitin, Tween 80, CM-cellulose and casein are not. Growth and acid formation occur with raffinose, salicin, lactose, melezitose, D-mannose, trehalose, melibiose, glucose, sucrose and maltose. Of the latter, raffinose, trehalose and sucrose are the best carbon sources. Mannitol, D-galactose, L-rhamnose, D-xylose, D-sorbose, D-sorbitol, D-fructose, inulin, D-arabinose, L-arabinose, D-ribose, inositol, citric acid, citrate, sorbic acid, succinate, glycerol, aspartic acid and L-tyrosine are not utilized. Alkaline phosphatase and weak lipase activities are present, but urease, tryptophan deaminase and arginine dihydrolase activities are absent. The major fatty acids $(>5 \%)$ are iso- $\mathrm{C}_{15: 1} \mathrm{G}(24.1 \%)$, iso$\mathrm{C}_{15: 0}(17.5 \%)$, anteiso- $\mathrm{C}_{15: 0}(9.5 \%)$, iso- $\mathrm{C}_{16: 0} \quad 3-\mathrm{OH}$ (7.7\%), iso- $\mathrm{C}_{17: 0} 3-\mathrm{OH}(7.7 \%)$, anteiso- $\mathrm{C}_{15: 1} \mathrm{~A}(7.4 \%)$ and iso- $\mathrm{C}_{15: 0} 3-\mathrm{OH}(7.4 \%)$. The $\mathrm{G}+\mathrm{C}$ content of the genomic DNA of the type strain is $40.6 \mathrm{~mol} \%$.

The type strain is $\mathrm{NJ}-44^{\mathrm{T}}$ (=CGMCC $1.6845^{\mathrm{T}}=\mathrm{NBRC}$ $103935^{\mathrm{T}}$ ), isolated from the sediment of Guanting Reservoir in Beijing, China.

\section{Acknowledgements}

This work was supported by a project from the Chinese National Natural Science Foundation (no. 30670071), the Hi-tech Research and Development Program (863 Program) of China (no. 2006AA10A213) and the Taihu Project (no. BK2007741) from Jiangsu Science and Technology Department. We make a grateful acknowledgement to the Associate Editor for his kind help in modification of the manuscript. We are indebted to Dr Jean Euzéby (Ecole Nationale Vétérinaire, Toulouse, France) for his kind assistance in Latin nomenclature.

\section{References}

Bernardet, J.-F., Nakagawa, Y. \& Holmes, B. (2002). Proposed minimal standards for describing new taxa of the family Flavobacteriaceae and emended description of the family. Int J Syst Evol Microbiol 52, 1049-1070.

Chun, J., Lee, J.-H., Jung, Y., Kim, M., Kim, S., Kim, B. K. \& Lim, Y. W. (2007). EzTaxon: a web-based tool for the identification of prokaryotes based on $16 \mathrm{~S}$ ribosomal RNA gene sequences. Int J Syst Evol Microbiol 57, 2259-2261.

De Ley, J. (1970). Reexamination of the association between melting point, buoyant density, and chemical base composition of deoxyribonucleic acid. J Bacteriol 101, 738-754.

Dong, X.-Z. \& Cai, M.-Y. (editors) (2001). Determination of biochemical properties. In Manual for the Systematic Identification of General Bacteria, pp. 370-398. Beijing: Science Press (in Chinese).

Garrity, G. M., Lilburn, T. G., Cole, J. R., Harrison, S. H., Euzéby, J. \& Tindall, B. J. (2007). The Taxonomic Outline of Bacteria and Archaea, release 7.7, part 11, The Bacteria: Phyla Planctomycetes, Chlamydiae, Spirochaetes, Fibrobacteres, Acidobacteria, Bacteroidetes, Fusobacteria, Verrucomicrobia, Dictyoglomi, Gemmatomonadetes, and Lentisphaerae, pp. 540-595. http://www.taxonomicoutline.org/

Johnson, J. L. (1985a). Determination of DNA base composition. Methods Microbiol 18, 1-31.

Johnson, J. L. (1985b). DNA reassociation and RNA hybridisation of bacterial nucleic acids. Methods Microbiol 18, 33-74.

Kämpfer, P., Young, C.-H., Sridhar, K. R., Arun, A. B., Lai, W. A., Shen, F. T. \& Rekha, P. D. (2006). Transfer of [Flexibacter] sancti, [Flexibacter] filiformis, [Flexibacter] japonensis and [Cytophaga] arversicola to the genus Chitinophaga and description of Chitinophaga skermanii sp. nov. Int J Syst Evol Microbiol 56, 2223-2228.

Kim, B.-Y., Weon, H.-Y., Yoo, S.-H., Hong, S.-B., Kwon, S.-W., Stackebrandt, E. \& Go, S.-J. (2007). Niabella aurantiaca gen. nov., sp. nov., isolated from a greenhouse soil in Korea. Int J Syst Evol Microbiol 57, 538-541.

Kumar, S., Tamura, K. \& Nei, M. (2004). MEGA3: integrated software for molecular evolutionary genetics analysis and sequence alignment. Brief Bioinform 5, 150-163.

Marmur, J. (1961). A procedure for the isolation of deoxyribonucleic acid from microorganisms. J Mol Biol 3, 208-218.

Thompson, J. D., Higgins, D. G. \& Gibson, T. J. (1994). ClustaL W: improving the sensitivity of progressive multiple sequence alignment through sequence weighting, position-specific gap penalties and weight matrix choice. Nucleic Acids Res 22, 4673-4680.

Weon, H.-Y., Kim, B.-Y., Yoo, S.-H., Lee, S.-Y., Kwon, S.-W., Go, S.-J. \& Stackebrandt, E. (2006). Niastella koreensis gen. nov., sp. nov. and Niastella yeongjuensis sp. nov., novel members of the phylum Bacteroidetes, isolated from soil cultivated with Korean ginseng. Int J Syst Evol Microbiol 56, 1777-1782.

Xie, C.-H. \& Yokota, A. (2006). Reclassification of [Flavobacterium] ferrugineum as Terrimonas ferruginea gen. nov., comb. nov., and description of Terrimonas lutea sp. nov., isolated from soil. Int J Syst Evol Microbiol 56, 1117-1121.

Ying, J.-Y., Liu, Z.-P., Wang, B.-J., Dai, X., Yang, S.-S. \& Liu, S.-J. (2007). Salegentibacter catena sp. nov., isolated from sediment of the South China Sea, and emended description of the genus Salegentibacter. Int J Syst Evol Microbiol 57, 219-222.

Zhu, F., Wang, S. \& Zhou, P.-J. (2003). Flavobacterium xinjiangense sp. nov. and Flavobacterium omnivorum sp. nov., novel psychrophiles from the China No. 1 glacier. Int J Syst Evol Microbiol 53, 853-857. 